\title{
Analysis of Heavy Metals in Human Hair Using Atomic Absorption Spectrometry (AAS)
}

\author{
Onuwa O. Peter, Ishaq S. Eneji ${ }^{*}$, Rufus Sha'Ato \\ Department of Chemistry and Centre for Agrochemical Technology, University of Agriculture, Makurdi, Nigeria \\ Email:"eneji3@yahoo.com
}

Received September 28, 2012; revised October 12, 2012; accepted October 20, 2012

\begin{abstract}
Hair samples of individual were analysed for heavy metals $(\mathrm{Cd}, \mathrm{Cr}, \mathrm{Pb}$ and $\mathrm{As})$ across gender and various occupational distributions by Atomic Absorption Spectrophotometric technique (AAS). The results of replicate analysis shows the following mean concentrations $(\mathrm{mg} / \mathrm{kg}): \mathrm{Cd}=27.8 \pm 8.0, \mathrm{Cr}=2.70 \pm 0.7, \mathrm{~Pb}=73.8 \pm 42.3$ and $\mathrm{As}=222 \pm 34.1$. The coefficients of variation for the total distribution is; $\mathrm{Cd}=28 \%, \mathrm{Cr}=26 \%, \mathrm{~Pb}=57 \%$ and $\mathrm{As}=15 \%$. The distribution of the metals follows the series in decreasing order of $\mathrm{As}>\mathrm{Pb}>\mathrm{Cd}>\mathrm{Cr}$, while their coefficients of variation is in the order of $\mathrm{Pb}>\mathrm{Cd}>\mathrm{Cr}>\mathrm{As}$. The result shows the presence of all the metals in relatively large amounts with As having the highest concentration between the two genders. The difference between male and female concentration could be due to individual differences in exposure to heavy metal load as a result of habitual or environmental factors.
\end{abstract}

Keywords: Heavy Metals; Human Scalp Hair; AAS; Concentration

\section{Introduction}

Research has shown that there is personal difference in concentrations of trace elements in the human hair according to human life or history such as occupation, sex, age, food, habit, social condition and so on [1]. Lemos et al. [2] have also reported that individual's deviation of elemental concentrations reflects the degree of environmental pollutants exposure to the human body, intakes of food and metabolism. Heavy metals, such as chromium, lead, mercury, cadmium, arsenic are extremely toxic even in very small amounts. When any of these elements is present in the environment at high concentrations, living organisms are subjected to strong natural selection for tolerance. Environmental contamination by metals exerts physiological pressures that are clearly too severe for survival of most species by means of phenotypic plasticity or physiological acclimation, rather than genetic adaptation [3]. Heavy metals are poisonous to living organisms including humans due to their biotoxic effects, which could be acute, chronic or sub-chronic, neurotoxic, carcinogenic, mutagenic or teratogenic [4]. Cadmium is toxic at extremely low level, it is also associated with bone defects like osteomalacia, increased blood pressure and myocardic dysfunctions. McCluggage [5] reported that severe exposure to cadmium may result in pulmonary oedema and death. Smoking has also been reported to be a contributing factor to higher bioaccumula-

${ }^{*}$ Corresponding author. tion of cadmium [6]. Chromium is an essential nutrient in our diet that helps insulin to maintain normal glucose level. Chromium toxicity can cause stomach upsets, ulcer, kidney-, liver-damage and even death. Femer [7] reported that lead is the most significant of the toxic heavy metals and the inorganic forms are absorbed through ingestion of food and water as well as inhalation. Apart from the teratogenic effects of lead, its poisoning also causes inhibition of the synthesis of haemoglobin, dysfunctions in the kidneys, joints and reproductive systems, acute and chronic damage to the central nervous system, etc. [8]. Workers with chronic headache and dizziness have higher levels of $\mathrm{Cr}$ and $\mathrm{Pb}$ in the scalp hair samples, such as in those working in a fireworks factory [9]. Arsenic toxicity symptoms depends on the chemical form ingested [10]. Arsenic acts to coagulate protein, forms complexes with coenzymes and inhibits the production of adenosine triphosphate during respiration [11].

Hair analysis is inexpensive and fast; it also detects and measures the content of heavy metals and minerals of the hair. The Global Environmental Monitoring System (GEMS) of the United Nations Environment Program selected human hair as one of the important monitoring materials for worldwide biological monitoring of pollution [12]. Therefore analyses of heavy metals $(\mathrm{Cr}$, $\mathrm{Pb}, \mathrm{Cd}$ and $\mathrm{As}$ ) in human scalp hair serves as an assessment for environmental contamination and can be used to sensitise individuals towards maintaining a healthier life style in their environments. 


\section{Materials and Methods}

All reagents (absolute ethanol, $\mathrm{HNO}_{3}, 20 \% \mathrm{H}_{2} \mathrm{O}_{2}$ ) used were analytical grade reagents obtained from Sigma Chemical Company, St Louis, USA. Atomic absorption spectrometer (Younglin AAS 8010) used was obtained from Younglin Instrument Ltd, South Korea.

\subsection{Sample Collection}

Freshly cut human hair samples were collected from the head of 51 individuals between the ages of 7 - 55 years (35 males and 16 females) across several occupational distributions within Makurdi metropolis in Central Nigeria (latitude $7^{\circ} 44^{\prime}$ and longitude $8^{\circ} 31^{\prime}$ ). The samples were quickly transferred in to coded polythene bags, sealed tightly and kept for pre-treatment. Prior to sample collection, questionnaires were distributed to respondents which contained highlights of information such as the gender, age, occupation, population density of residential area, type of food consumed, water source, presence of refuse dump in the area of residence, behavioural pattern etc. Height and body mass of the consenting individuals were also taken.

\subsection{Sample Cleaning/Digestion}

The hair samples collected were cut to about 200 - 250 mg using stainless steel scissors rinsed in ethanol, then coded and stored. The stored samples were further cut into approximately 0.125 in $(0.3 \mathrm{~cm})$ pieces and mixed to allow a representative subsampling of the hair specimens and were washed according to the recommendation of International Atomic Energy Agency (IAEA) [13]. Exactly $0.1065 \mathrm{~g}$ of hair sample was weighed accurately into a $50 \mathrm{~mL}$ crucible. The sample was covered with 8 $\mathrm{mL}$ conc. $\mathrm{HNO}_{3}$, after which the crucible was covered with the crucible lid and placed on a hot plate. Hair was digested at $70^{\circ} \mathrm{C}-85^{\circ} \mathrm{C}$ for about 25 minutes or until the hair is completely digested and the solution becomes clear. The crucible was not allowed to go dry until the digestion was complete. After cooling to room temperature inside the fume hood, $1 \mathrm{~mL}$ of $30 \% \mathrm{H}_{2} \mathrm{O}_{2}$ was added to each sample, and heated again on hot plate at the lowest setting (first setting i.e. $42^{\circ} \mathrm{C}$ ) just until bubbling stops. After this, heat was increased to about $80^{\circ} \mathrm{C}$ or as needed until the volume is reduced to about $2.5 \mathrm{~mL}$ [14]. The contents of each crucible were quantitatively transferred to a cleaned and dried $100 \mathrm{~mL}$ volumetric flask. The digestion vessel was rinsed three times with $1.5 \mathrm{~mL}$ each with deionised water and added to the volumetric flask and made up to volume with deionised water. (It could be filtered using Whatman paper no. 1 and no. 40 if the solution looks cloudy to prevent clogging the nebulizer). It was then transferred to a cleaned sample bottle, corked, labelled well and stored in the refrigerator until ready to be analysed. Standard solutions of all the metals investigated were prepared from concentration levels of $1-20$ ppb.

\section{Results and Discussion}

The results of AAS analysis shows, the ranges in concentrations of heavy metals $(\mathrm{mg} / \mathrm{kg})$ as follows: $\mathrm{Cr}$ varies from 0.33 - 16.16; $\mathrm{Pb}$ varies from 5.80 - 347.19; $\mathrm{Cd}$ ranges from 2.46 - 130.17 while As ranges from 21.29 447.04. Table 1 shows the distribution of heavy metals among male samples by age with As having the highest concentration $(243 \pm 125 \mathrm{mg} / \mathrm{kg})$ within 21 - 31 years of age interval.

The distribution of the metals among female samples by age are shown in Table 2, where all the metals analysed were more distributed around age bracket of 21 31 years except $\mathrm{Cd}$ where the highest was between 7 - 20 years. The distribution and the average concentration of heavy metals by age in the entire samples is shown in Table 3 in which $\mathrm{Cr}$ has the least concentration but has a high value between the ages $21-31$ and $\geq 43$ and As has the highest concentration followed by $\mathrm{Pb}$ and $\mathrm{Cd}$.

The total mean concentrations of the metals $(\mathrm{mg} / \mathrm{kg})$ were $\mathrm{Cr}=2.70 \pm 0.7, \mathrm{Cd}=27.8 \pm 8.0, \mathrm{~Pb}=73.8 \pm 42.3$ and As $=222 \pm 34.1$ as also shown in Figure 1. This shows that As has the highest and $\mathrm{Cr}$ the least concentration. The total coefficient of variation were; $\mathrm{Cr}=26 \%$, $\mathrm{Cd}=29 \%, \mathrm{~Pb}=57 \%$, and $\mathrm{As}=15 \%$. This indicates that

Table 1. Distribution and mean concentration $(\mathrm{mg} / \mathrm{kg})$ of heavy metal in male samples by age.

\begin{tabular}{|c|c|c|c|c|}
\hline \multirow{2}{*}{$\begin{array}{l}\text { Range } \\
\text { (years) }\end{array}$} & \multirow{2}{*}{$\begin{array}{l}\text { Number } \\
\text { of male }\end{array}$} & \multicolumn{3}{|c|}{ Heavy metals } \\
\hline & & $\mathrm{Cd}$ & $\mathrm{Pb}$ & As \\
\hline $7-20$ & 4 & $4.31 \pm 4.1040 .5 \pm 5.90$ & $104 \pm 73.7$ & $241 \pm 210$ \\
\hline $21-31$ & 19 & $3.57 \pm 4.0028 .7 \pm 22.2$ & $42.4 \pm 30.3$ & $243 \pm 125$ \\
\hline $32-42$ & 7 & $1.64 \pm 0.9020 .1 \pm 12.0$ & $24.6 \pm 30.0$ & $181 \pm 114$ \\
\hline$\geq 43$ & 5 & $3.66 \pm 2.6028 .5 \pm 21.9$ & $60.8 \pm 4.10$ & $211 \pm 133$ \\
\hline
\end{tabular}

Table 2. Distribution and mean concentration (mg/kg) of heavy metal in female samples by age.

\begin{tabular}{|c|c|c|c|c|c|}
\hline \multirow{2}{*}{$\begin{array}{l}\text { Range } \\
\text { (years) }\end{array}$} & \multirow{2}{*}{$\begin{array}{c}\text { Number } \\
\text { of } \\
\text { female }\end{array}$} & \multicolumn{4}{|c|}{ Heavy metals } \\
\hline & & $\mathrm{Cr}$ & $\mathrm{Cd}$ & $\mathrm{Pb}$ & As \\
\hline $7-20$ & 5 & $1.08 \pm 0.800$ & $31.9 \pm 0$ & $127 \pm 78.3$ & $298 \pm 0$ \\
\hline $21-31$ & 10 & $2.60 \pm 2.10$ & $27.0 \pm 17$ & $194 \pm 158$ & $223 \pm 200$ \\
\hline $32-42$ & - & - & - & - & - \\
\hline$\geq 43$ & 1 & $0.72 \pm 0.00$ & $2.46 \pm 0.00$ & $40.51 \pm 0.00$ & Nil \\
\hline
\end{tabular}


Table 3. Summary of distribution and average concentration $(\mathrm{mg} / \mathrm{kg})$ of heavy metal in the 51 samples by age.

\begin{tabular}{|c|c|c|c|c|}
\hline Range (years) & Heavy metals & & & \\
\hline & $\mathrm{Cr}$ & $\mathrm{Cd}$ & $\mathrm{Pb}$ & As \\
\hline $7-20$ & $2.70 \pm 3.23$ & $38.8 \pm 6.37$ & $118 \pm 67.7$ & $260 \pm 153$ \\
\hline $21-31$ & $3.28 \pm 3.56$ & $28.2 \pm 20.3$ & $98.4 \pm 121$ & $233 \pm 144$ \\
\hline $32-42$ & $1.64 \pm 0.94$ & $20.1 \pm 12.0$ & $24.6 \pm 30.0$ & $181 \pm 114$ \\
\hline$\geq 43$ & $3.17 \pm 2.58$ & $24.2 \pm 22.3$ & $54.0 \pm 12.0$ & $211 \pm 133$ \\
\hline
\end{tabular}

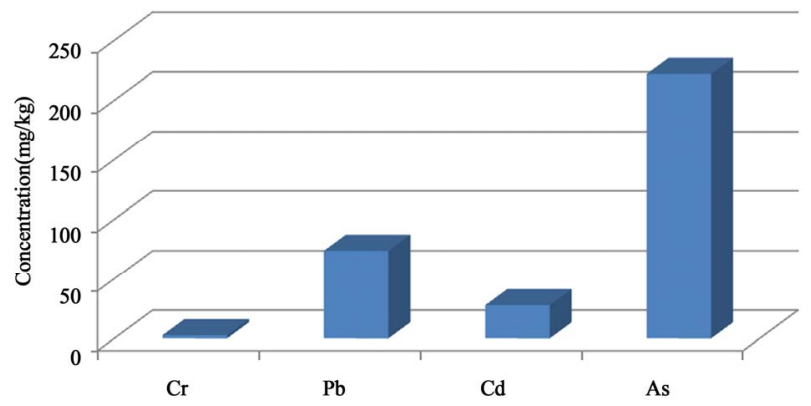

Figure 1. Total mean distribution of individual heavy metals using AAS technique.

lead has the highest coefficient of variation while arsenic has the least. Since coefficient of variation is a measure of dispersion, the implication is that while lead is widely dispersed among the sampled population, arsenic is more closely dispersed within same sample population. Based on AAS analysis, the average concentration of $\mathrm{Cr}$, and $\mathrm{Cd}$ are higher in males while that of $\mathrm{Pb}$ and $\mathrm{As}$ are higher in females as shown in Figures 2 and 3. According to Lee et al [15] this could be attributed to use of cosmetic products by females among other sources.

The standard deviation is higher in females for $\mathrm{Pb}$ and $\mathrm{Cd}$ while it is higher for $\mathrm{Cr}$ in males. This indicates that the deviation in the individual content of heavy metals is more pronounced in females compared to males. The coefficient of variation $(\mathrm{CV})$ for $\mathrm{Cr}, \mathrm{Cd}$ and $\mathrm{As}$ are higher in females except $\mathrm{Pb}$ which is higher in males.

The mean concentration of heavy metals in both males and females were compared statistically at 0.05 probability which showed significant difference in all the elemental content. Similar samples analysed by x-ray fluorescence analysis showed that the average concentrations of $\mathrm{Cr}$ in XRF method for both genders were relatively higher than that in AAS method [16]. This is likely due to the non-destructive nature of sample matrix used in $\mathrm{XRF}$ analysis as the samples were not digested before analysis [17], where as, the samples for AAS were completely digested before analysis. This could lead to loss of volatile proportion of analytes. Also, a difference was observed between the concentration of $\mathrm{Cr}$ in XRF technique and AAS method when compared statistically [16].

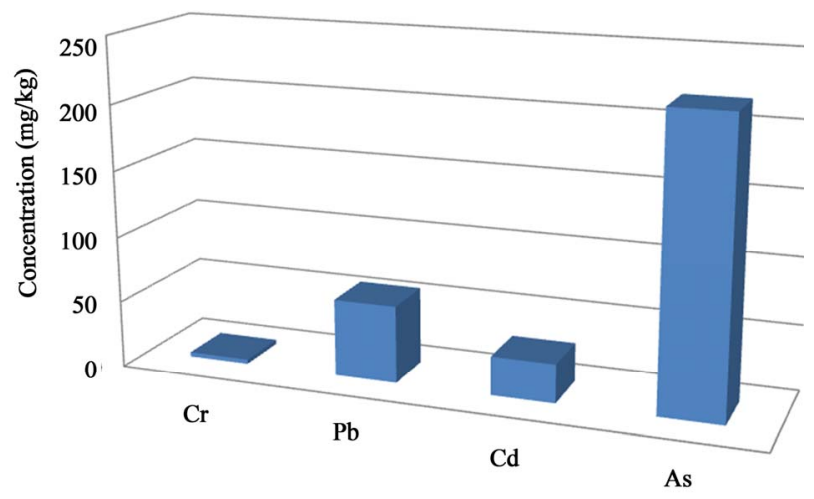

Figure 2. Average concentration of heavy metals in males using AAS technique.

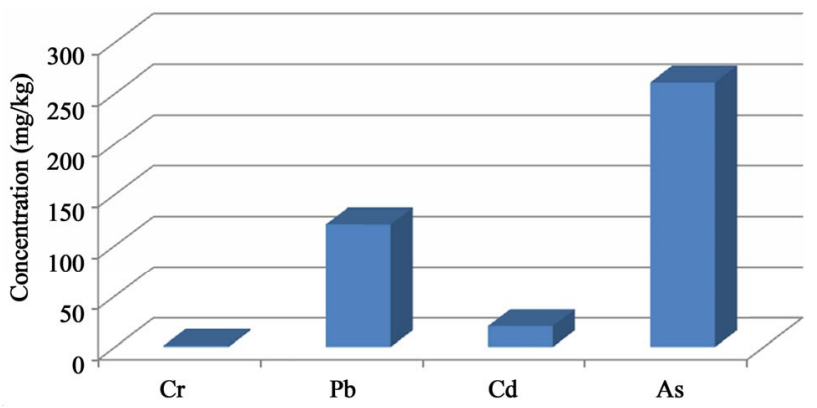

Figure 3. Average concentration of heavy metals in females using AAS technique.

The difference between the concentration of the same element $(\mathrm{Cr})$ in same gender under two methods where as, it showed no difference under same method could have resulted from method variability such as sensitivity, detection limit, analytical conditions of instrument, pretreatment methods, possibility of the sample matrix being contaminated by exogenous material and the efficiency of the analyst $[12,18]$. The difference between male and female concentration could be due to individual differences in heavy metal load as a result of habitual or environmental factors.

The distribution of the metals follows the series: As $>$ $\mathrm{Pb}>\mathrm{Cd}>\mathrm{Cr}$, while their general coefficients of variation is of the order: $\mathrm{Pb}>\mathrm{Cd}>\mathrm{Cr}>$ As. This showed that $\mathrm{Pb}$ recorded the highest variation in the distribution among individual respondents as compared to As which has the least. Lead has diffuse possible sources which could be from drinking water, which for most respondents were tap water (boilers ring in the pipes) and bore holes. Others are packaging materials, contaminated food grown in lead-deposited soils either from point or non-point sources, use of agrochemicals during cropping season, use of leaded fuels, lead plate accumulators, use of alloys like solder, bearing metals, type metals etc. The high accumulation of As could have resulted from the use of insecticides, doping agents in semi-conductors, use of some lead-based alloys to promote hardening etc. [19]. 


\section{Conclusion}

Analysis carried out by AAS technique for As, $\mathrm{Cd}, \mathrm{Cr}$ and $\mathrm{Pb}$ indicates the presence of all the metals in relatively large amounts with As having the highest concentration across age distribution and between the two genders. The presence of all the heavy metals under investigation is a clear indication of the environmental content as well as the behavioural pattern of the respondents who are randomly selected from the general society. As and $\mathrm{Pb}$ were much higher in females than males probably due to use of cosmetics formulations and hair treatment among them. For all the four different heavy metals determined, the coefficients of variation were higher for three elements $(\mathrm{Cr}, \mathrm{Cd}$ and $\mathrm{Pb})$ among the females while only $\mathrm{As}$ has higher coefficient of variation among the males. This reflects $75 \%$ of the total population which indicates that these metals have greater degree of dispersion among the female population than the males.

\section{Acknowledgements}

Our appreciation goes to individuals that filled our questionnaire and also volunteered their scalp hair samples to be used for this investigation without any reservation. We are grateful to Mallam Kabiru of Department of Science Laboratory Technology, Kaduna Polytechnic, for his assistance during the AAS analysis. We are also grateful to anonymous reviewers' comments/suggestions

\section{REFERENCES}

[1] S. J. Steindel and P. J. Howanitz, "Uncertainty of Hair Analysis for Trace Metals," Journal of Amercan Medical Association, Vol. 285, No. 1, 2001, pp. 83-85. doi:10.1001/jama.285.1.83

[2] P. C. D. Lemos, H. M. Dung, Vu C. Dong, Sy, N Thi and N. M. Sinh, "Analysis of Angolan Human Hair Samples by the $\mathrm{K}_{0}$ - NAA Technique on the Dalat Research Reactor: The Study and Application on the $\mathrm{K}_{\mathrm{o}}$-Standardization Method of Neutron Activation Analysis at Dalat Nuclear Reasrch Institute(NRI), Vietnam," Proceedings of the 5th Asian Workshop on Utilization Reserch Reactors, Jakarta, 2005.

[3] R. V. Bharathi, A. J. Suresh, M. Thirumal and B. Kumudhaveni, "Analysis of Heavy Metal and Inorganic Element Content in Barringtonia acutangula Leaf," Ethnobotanical Leaflets, Vol. 14, 2010, pp. 856-863.

[4] J. O. Duruibe, M. O. C. Ogwuegbu and J. N. Egwurugwu, "Heavy Metal Pollution and Human Biotoxic Effects," International Journal of Physical Sciences, Vol. 2, No. 5, 2007, pp. 112-118.

[5] D. McCluggage, "Heavy Metal Poisoning," NCS Maga- zine, 1991

www.cocktatiels.org/articles/Diseases/Metals.html.

[6] P. Chattopadhyay, H. Joshi and K. Samaddar, "Hair Cadmium Level of Smoker and Non-Smoker Human Volunteers in and around Calcutta City," Bulletin of Environmental Contamination and Toxicology, Vol. 45, No. 2, 1990, pp. 177-180. doi:10.1007/BF01700180

[7] D. J. Ferner, "Toxicity, Heavy Metals," eMed.J. Vol. 2, No. 5, 2001, p. 1.

[8] M. O. C. Ogwuegbu and W. Muhanga, "Investigation of Lead Concentration in the Blood of People in the Copperbelt Province of Zambia," Journal of Environment, Vol. 1, 2005, pp. 66-75.

[9] A. Sukumar and R. Subramanian, "Elements in Hair and Nails of Urban Residents of New Delhi, CHD Hypertensive and Diabetic Cases," Biological Trace Element Research, Vol. 34, No. 1, 1992, pp. 89-97. doi:10.1007/BF02783901

[10] J. R. Holum, "Elements of General and Biological Chemistry," 6th Edition, John Wiley and Sons, New York, 1983.

[11] Institute of Environmental Conservation and Research (INECAR), "Position Paper against Mining in Rapu-Rapu," NECAR, Ateneo de Naga University, 2000. www.adnu.edu.ph/institutes/Inecar/pospaper1.asp

[12] G. Dodd, "Heavy Metal Poising and Hair Analysis," 2010. http://holisticvetpetcare.com/pdf/HeavyMetalpoisonhair Analysis-2.pdf

[13] J. Md Khudzari, H. Wagiran, Md. I. Hossain, N. Ibrahim and M. A. Agam, "Heavy Metals $\mathrm{Mn}, \mathrm{Fe}, \mathrm{Ni}, \mathrm{Cu}$ and $\mathrm{Zn}$ in Human Hair Sample Using Energy Dispersion X-Ray Fluorescence Analysis," International Journal of Physical Science, Vol. 6, No. 8, 2011, pp. 2090-2094.

[14] A. Johansen, "Environmental Health: Science, Policy and Social Justice Winter Quarter," Central Washington University, Ellensburg, 2010.

[15] S. M. Lee, H. J. Jeong and I. S. Chang, "Simultaneous Determination of Heavy Metals in Cosmetic Products," Journal of Cosmetic Science, Vol. 59, No. 5, 2008, pp. 441-448.

[16] O. P. Onuwa, "Determination of Heavy Metals in Human Hair," M.Sc. Thesis, Department of Chemistry, University of Agriculture, Makurdi, 2012.

[17] D. A. Bass, D. Hickok, D. Quig and K. Urek, "Trace Element Analysis in Hair: Factor Determinig Accuracy, Precision and Reliability," Alternative Medicine Review, Vol. 6, No. 5, 2001, pp. 472-481.

[18] S. M. DeAntonio, S. A. Katz, D. M. Schiner and J. D. Wood, "Anatomically Related Variations in Trace-Metal Concentrations in Hair," Clinical Chemistry, Vol. 28, No. 12, 1982, pp. 2411-2413.

[19] "Oxford Dictionary of Chemistry," 6th Edition, Oxford University Press, New York, 2008. 